\title{
Obtaining of Trialkylphosphates in Anodic Dissolution of Copper Phosphide
}

\author{
A.P. AUESHOV ${ }^{1}$, S. SATAYEV ${ }^{2}$ and A.S. TUKIBAYEVA ${ }^{3 *}$ \\ Laboratory of Physico-chemical methods of researches ${ }^{1}$, Department of Chemical \\ Technology of inorganic substances ${ }^{2}$, Department of Nanotechnology ${ }^{3}$, M.Auezov \\ South Kazakhstan State University, South-Kazakhstan region, Republic of Kazakhstan . \\ ${ }^{*}$ Corresponding author E-mail: tukibayeva @ inbox.ru \\ http://dx.doi.org/10.13005/ojc/300413
}

(Received: July 26, 2014; Accepted: September 10, 2014)

\begin{abstract}
Due to obtain trialkylphosphate is suggested to use anodic solution of copper phosphide in alcohol solutions. At this, it can use copper phosphide, obtained at the processing of wastes of phosphorus production. Moreover, it is presented ways of obtaining of tri- $n$-butylphosphate and tri-izo-butylphosphate.
\end{abstract}

Key words: trialkylphosphate, tri-n-butylphosphate, tri-izo- butylphosphate, Copper phosphide, electrosyntheses, sacrificial anodes.

\section{INTRODUCTION}

In the research ${ }^{1,2}$ are shown the possibilities of obtaining of trialkylphosphate by the electrolysis of suspensions of red phosphorus. The authors of work ${ }^{3}$ used dialkylphosphoric acid as the initial phosphorus containing compounds for synthesis of trialkylphosphate. Next authors ${ }^{4}$ studied the process of synthesis of tryalkyl phosphates, i.e., derivatives of methanol, butanol, and diethylene glycol, by anodic oxidation of dimethyl phosphite in the corresponding alcohol. It was found that three alkyl phosphates corresponding to the three possible combinations of substituents bound to phosphorus in phosphate are formed.

In this regard, it was interesting to investigate the possibilities of obtaining of trialkylphosphates by the using of sacrificial copperphosphorus anode as a donor of phosphorus. The copper-phosphorus alloys are produced by industries, in addition, these alloys are formed at the processing of phosphorus sludge ${ }^{5}$. 
Mechanism of anodic dissolution of copper-phosphorus alloys in the alcohol solutions of hydrogen chloride can be represented by the following equations:

$$
\begin{aligned}
& \mathrm{Cu}+\mathrm{Cl}{ }^{\circledR} \mathrm{CuCl}+\mathrm{e} \\
& \mathrm{Cu} 3 \mathrm{P}+\mathrm{Cl}^{-} \rightarrow 3 \mathrm{CuCl}+\mathrm{P}+3 e
\end{aligned}
$$

$3 \mathrm{CuCl}+3 \mathrm{ROH} \rightarrow P(\mathrm{RO})_{3}+3 \mathrm{HCl}+3 \mathrm{Cu}$, where $\mathrm{R}$ - Alkyl radical

The formed phosphides are subjected to further oxidation. This process may proceed on the anode or in solution with the participation of oxygen or copper compounds. In the latter case, the reaction may be in the form

$$
\begin{aligned}
& 2 \mathrm{CuCl}+\mathrm{P}(\mathrm{RO})_{3}+2 \mathrm{ROH} \circledast \mathrm{OP}(\mathrm{RO})_{3}+2 \mathrm{HCl}+\mathrm{ROR} \\
& +2 \mathrm{Cu}
\end{aligned}
$$

Trialkylphosphates are the efficient complex forming reagents. Particularly, in this regard the valuable substances are tri- $n$-butylphosphate and tri-izo-butylphosphate, which are used for selective extractions of uranium, thorium ${ }^{6}$. Currently, these reagents are used in nuclear fuel engineering, therefore the development of new methods of the obtaining of trialkylphosphate presents practical interest.

\section{MATERIALAND METHODS}

\section{Electrosynthesis of tri-n-butylphosphate}

In glass electrolyzer, equipped by water jacket and return refrigerator $200 \mathrm{~cm}^{3}$ of $\mathrm{n}$-butane alcohol was loaded. Previous of electrolyzing the alcohol was saturated by dry gaseous hydrogen chloride. In this purpose it is very convenient to obtain the dry hydrogen chloride by the action of concentrated sulfuric acids on concentrated hydrochloric acid with the followed passing of hydrogen chloride through a flask with concentrated $\mathrm{H}_{2} \mathrm{SO}_{4}$.

A plate of copper - phosphorus alloys (phosphorus content is 10 mass \%) weighing $112 \mathrm{~g}$ with the total area $3.5^{\prime \prime} 10^{-3} \mathrm{~m}^{2}$, and working surface $2.5^{\prime \prime} 10^{-3} \mathrm{~m}^{2}$, the copper plates cathodes with analogous size were used in electrolysis.
Electrolysis was performed at current density of $0.25-0.30 \mathrm{~A} / \mathrm{m}^{2}$ "' $10^{-4}$ during 5 hours. Temperature of an electrolyte was $65-70^{\circ} \mathrm{C}$. The voltage on the bath was not exceeding 20-22 W. The passed current, which was measured by copper coulometer, was 35 ampere hour (A.h). At this, in the results the electrolysis was dissolved $29.6 \mathrm{~g}$ of copper phosphide anode. $25.2 \mathrm{~g}$ of copper powder was isolated on the cathode, the part of which fell to the bottom of the electrolysis.

After filtration, the solution was subjected to vacuum distillation. The unreacted butyl alcohol was distilled off at the temperature $32-35^{\circ} \mathrm{C}$ and the pressure $2.66^{\prime \prime} 10^{3} \mathrm{~Pa}$. The white deposit of copper monochlorides was precipitated in the remains, which it was filtered off. Weight of precipitate after drying was $3.1 \mathrm{~g}$. The volume of filtrate was $30 \mathrm{~cm}^{3}$. Moreover, to this filtrate $60 \mathrm{~cm}^{3}$ of benzene were added and were mixed for 5-6 minutes, after that the solution was poured into the separating funnel and washed out with $40 \mathrm{~cm}^{3}$ of distilled water until the disappearances of blue color of copper ions in the aqueous layer. The benzene layer was filtered through anhydrous sodium sulfate. After distillation of benzene from liquid leavings by the vacuum distillation at a temperature of $159-165^{\circ} \mathrm{C}\left(1.60^{\prime \prime} 103\right.$ $\mathrm{Pa}) 20 \mathrm{~cm}^{3}$ of liquid containing phosphorus was obtained.

\section{Electrosyntheses of tri-izo-butylphosphate.}

Electrolysis with $300 \mathrm{~cm}^{3}$ of isobutyl alcohol (2-methyl-3-propanol), also previously saturated by hydrogen chloride was performed on the above presented procedure, the electrolysis performed at the current density of $i_{a}=(0.2-0.25) " 10^{-4} \mathrm{~A} / \mathrm{m}^{2}$ and $U=20-24 \mathrm{~W}$. At these conditions $60 \mathrm{~A} /$ hours of electricity was passed through the electrolyte. The loss of anode mass was $46.1 \mathrm{~g}$.

Further processing of electrolyte was conducted same ways, as tri- $n$-butylphosphate. After distillation of benzene, $35 \mathrm{~cm}^{3}$ of tri-izobutylphosphate was remained, which has been subjected to vacuum distillation5

\section{RESULTS AND DISCUSSION}

\section{Electrosyntheses of tri-n-butylphosphate}

The density of tri-n-butylphosphate was 
determined by State standard 18995.1-73 p. $2^{7}$. The analysis of phosphorus in trialkylphosphate was conducted by Kjeldahl ${ }^{8}$. Determination of the refractive index was implemented according to State standard 18955.6-739.

The boiling point of tri-n-butylphosphate was determined according to State standard 18995.6-73, p.1. IR-specters are taken by the «SPEKORD-IR», of Germany Company "Carl Seis, lena".

Quantitative analysis indicated, that the liquid contains about $11.09 \%$ of phosphorus. Determination the boiling point, density, refractive index and take IR-spectra are gave the following results:

Boiling point $-289.6^{\circ} \mathrm{C}$ (at $9,806.10^{4}$ )

Density, $\mathrm{g} / \mathrm{cm}^{3} \quad-0.9720$

Refractive index - 1.4261

Character absorptions in the IR-specter

$$
\begin{array}{r}
-1000-1100 \mathrm{~cm}^{-1} \quad \text { P-O-C (valent) } \\
-1274 \mathrm{~cm}^{-1} \quad \mathrm{P}=\mathrm{O} \text { (valent) } \\
-730 \mathrm{~cm}^{-1} \quad \text { P-O (sym.valent). }
\end{array}
$$

These data allowed us to identify the product as tri- $n$-butylphosphate.

We conducted the calculation the yield of tri-n-butylphosphate containing phosphorus, as well as other trialkylphosphates by the following. In each experiment the amount of phosphorus, which passed into the solution, was analytically determined. In general, this value was about $9.8 \%$ of the total amount of copper - phosphorus alloys. Then, on the basis of reaction of formation, we determined the theoretical amounts of trialkylphosphate.

Thus, $29.6 \mathrm{~g}$ of copper-phosphorus alloy was dissolved at the electrolysis, and $26.9 \times 0.098$ $=2.90 \mathrm{~g}$ of phosphorus passed into the solution. Theoretical amount of tri-n-butylphosphate was $266 \times 2.90 / 31=24.88 \mathrm{~g}$

The measured weight of $20 \mathrm{~cm}^{3}$ of tri-nbutylphosphate was equal to $19.40 \mathrm{~g}$, i.e., the output of tri-n-butylphosphate was $77.9 \%$.

\section{Electrosyntheses of tri-izo-butylphosphate}

In the result of distillation under pressure of $1.064 " ' 10^{2} \mathrm{~Pa}$, at the corresponding temperatures (T) were obtained the following (G) substances.

1) $\mathrm{T}=86-87^{\circ} \mathrm{C}, \mathrm{G}-10 \mathrm{~g}$

2) $\mathrm{T}=110-112^{\circ} \mathrm{C}, \mathrm{G}-7 \mathrm{~g}$

3) $\mathrm{T}=120-130^{\circ} \mathrm{C}, \mathrm{G}-12 \mathrm{~g}$

In each of these fractions were determined the content of phosphorus $(P)$ and refractive index $\left(n^{20}\right)$.
1) $P=10.3 \%, \quad n^{20}=1.4198$
2) $P=10.6 \%, \quad n^{20}=1.41983$
3) $P=12.1 \%, \quad n^{20}=1.4222$

As it is evident from the cited data, that first and second fractions have similar values by the contents of phosphorus and same refractive indixes. The third fraction is different by phosphorus content. However, all three fractions gave exactly the same IR-spectra, identical IR-specters of tri-izobutylphosphate ${ }^{10}$.

On the basis of these data, we got product, which was identified as tri-izo-butylphosphat. Output of the amount of phosphorus was $71.11 \%$.

\section{REFERENCES}

1. Blizniuk, N.K.; Kolomies, A.F.; Barshavsky, S.L.; Skladiev, A.A.; Korman, L.P.; Tkachenko, G.B.; Libman, B.Y.; Novokreshenov, G.A. RU IC 152334 (1974)

2. Varshavsky, S.L.; Tomilov A.P.; Smirnov, Y.D. J. All-Union Chemical Society named after D.I. Mendeleyev, 1962, 5, 598 - 605

3. Ohmori, H.; Nakai, S. Chem. Pharm.Bull.,
1979, 27, 1700

4. Berezkin, M.Yu.; Turygin, V.V.; Khudenko, A.V.; Zhestkov, S.A.; Kuz'mina, N.E.; Tomilov, A.P.; Fokin, E.A. Russ. J. Electrochem., 2011, 47, 10

5. Chernogorenko V.B., Chemical technology of phosphides and alloys, containing phosphorus, IPM, Kiev, (1979) 
6. Purdella D., Vilchanu R., Chemistry of organic compounds of phosphorus, Chemistry, Moscow, (1972)

7. State standard 18995.1-73, Liquid chemical products. Methods for determination of density

8. Franke Z., France P., Barnke B., Chemistry damaging substances, Vol.2, Chemistry, Moscow, (1977)

9. tate standard 18955.6-73, Organic chemical products. Methods for determination of boiling point.

10 Atlas of IR-specters of organic concerning phosphorus, Chemistry, Moscow, (1972) 